\title{
Origin of the foraminifera
}

\author{
(ribosomal RNA/phylogeny/protists/paleontology)
}

\author{
Charles G. Wray $\dagger$, Martin R. Langer $\ddagger$, Rob DeSalle*, John J. Lee§, And Jere H. Lipps $\ddagger$ \\ Departments of *Entomology and §Invertebrates, American Museum of Natural History, CPW @ 79th Street, New York, NY 10024; and ‡Department of \\ Integrative Biology, Museum of Paleontology, University of California, Berkeley, CA 94720
}

Communicated by James W. Valentine, University of California, Berkeley, CA, September 13, 1994

\begin{abstract}
We report nuclear small-subunit rDNA sequences for two species of the benthic foraminifer Ammonia. Because of their abundance in present and past seas, the foraminifera are a very important group of organisms used in a wide range of geologic studies; however, the ancestry of this group was, until now, unknown. Difficulties in purifying foraminiferal DNA and avoiding PCR contamination led us to develop DNA.DNA in situ hybridization techniques to verify our sequence data. Phylogenetic analysis of verified foraminiferal DNA sequence indicates these taxa are a divergent, "alveolate" lineage, within the major eukaryotic radiation. Our findings cast doubt upon the assumption that all foraminifera are derived from an amoebalike ancestor. Cytological features and the DNA sequences presented herein suggest that the foraminifera were derived from a heterokaryotic flagellated marine protist, probably sometime in the later Proterozoic.
\end{abstract}

The foraminifera first appear in the Cambrian and radiate into tens of thousands of species during the Phanerozoic, with some 4000 extant species living today (1). They are a major group in the fossil record and derived paleontologic data are extensively utilized for biostratigraphic, paleoenvironmental, and paleoceanographic interpretations $(2,3)$. In spite of this wealth of knowledge, the phylogenetic relationship of foraminifera to other eukaryotes remains unclear.

Although foraminifera are characterized by their anastomosing, granular reticulopodia $(4,5)$, other marine protists possess this character as well $(6,7)$. Hence this diagnostic character is equivocal in the phylogenetic recognition of the foraminifera. A further lack of shared morphologic features has made phylogenetic placement of the foraminifera difficult, and phylogenetic assessments are generally based upon untested assumptions. Because of the unlikely preservation of probable foraminiferal ancestral protists and the appearance of complete, test-bearing foraminifera in the Cambrian $(8,9)$, paleontologic data yield no direct evidence concerning foraminiferal origins. A recent hierarchical classification placed the foraminifera within phylum Rhizopoda (von Siebold), associated with the Lobosea (Carpenter), Entamoebidea (Cavalier-Smith), Filosea (Leidy), and Xenophyophorea (Schulze) (10). Previous workers also assumed that the group arose from an amoeba-like ancestor (11).

We investigated the phylogenetic status of the foraminifera through molecular systematic analysis of nuclear small-subunit (18S) rDNA sequence. The foraminifera were one of the major remaining groups for which $18 \mathrm{~S}$ rDNA sequence was not yet characterized. DNA is difficult to purify from foraminifera because they ingest various different eukaryotic food organisms and many species possess eukaryotic epibionts on their surfaces and algal symbionts on and in their cells. Nevertheless, we successfully obtained $18 \mathrm{~S}$ rDNA sequence data from two widely distributed and common, marginal marine species of Ammonia.

The publication costs of this article were defrayed in part by page charge payment. This article must therefore be hereby marked "advertisement" in accordance with 18 U.S.C. $\$ 1734$ solely to indicate this fact.

\section{MATERIALS AND METHODS}

We report a complete and a partial DNA sequence for the $18 \mathrm{~S}$ rDNA from the nonsymbiont-bearing, benthic foraminifera Ammonia beccarii (Linne) and Ammonia aberdoveyensis (Haynes), collected and sequenced independently by our two laboratories using different technical approaches." $A$. beccarii was collected in North Sea Harbor, Peconic Bay, New York, and $A$. aberdoveyensis was collected in San Francisco Bay, California. DNA extraction, cloning, and sequencing from $A$. beccarii and $A$. aberdoveyensis are described elsewhere $(12,13)$. Briefly, the complete $18 \mathrm{~S}$ rDNA gene for $A$. beccarii was amplified using PCR, cloned using the PCR 2000 kit (Invitrogen), and sequenced after sodium hydroxide denaturation (14). Partial sequence for $A$. aberdoveyensis was directly sequenced from single-stranded PCR amplifications (13).

To test for possible PCR-generated contamination, we verified the sequence from $A$. beccarii with digoxigenin-labeled speciesspecific $18 \mathrm{~S}$ rDNA probes (Fig. 1). Digoxigenin labeled probes were generated by PCR incorporation of digoxigenin-dUTP using Boehringer Mannheim Biochemicals (BMB) direct specifications. PCR primers for probe synthesis are labeled in Fig. 1. The variable region probes (Fig. 1) were generated by PCR for $A$. beccarii, the foraminiferal endosymbiotic dinoflagellate Symbiodinium sp., and the diatom Nitzshia sp. (food source for foraminiferal cultures). The dinoflagellate, diatom, and blind (no DNA) probes were used as controls for the in situ hybridization experiments. Whole foraminifera were treated with RNase and proteinase $\mathrm{K}$ for $5 \mathrm{~min}$ each at $37^{\circ} \mathrm{C}$ and fixed in $0.4 \%$ formaldehyde at $4^{\circ} \mathrm{C}$. After addition of probe, cellular DNA was denatured at $95^{\circ} \mathrm{C}$ for $6 \mathrm{~min}$. Denaturation is followed by a $1-\mathrm{min}$ incubation at $0^{\circ} \mathrm{C}, 3-\mathrm{hr}$ incubation at $45^{\circ} \mathrm{C}$, and the following washes: twice in $2 \times$ sodium chloride/sodium citrate (SSC) at $20^{\circ} \mathrm{C}$, once in $0.1 \times \mathrm{SSC}$ at $45^{\circ} \mathrm{C}$. Probe detection follows the BMB standard protocol. After the color reaction was terminated, foraminifera were crushed and mounted in glycerol, aqueous mounts. Feulgen nuclear staining was also used to investigate the nuclei found in $A$. beccarii (16). Sequence alignments were generated using a parallel processing version of MALIGN (15) run on 11 Hewlett-Packard HP735s with the following input parameters: gap-to-change cost 2:1, 4:1, 8:1 (one for each of three alignments); alignswap, treeswap, quick, and iter. MALIGN produces repeatable alignments based upon minimizing the total cost of all nucleotide substitutions and/or insertion of gaps. Visual inspection of alignments generated by MALIGN and consideration of secondary structural constraints were undertaken to determine and remove the ambiguously aligned nucleotide positions within hypervariable regions. All other eukaryotic $18 \mathrm{~S}$ rDNA sequences were taken from the National Center for Biotechnology Information release 7.0. Phylogenetic hypotheses were generated using either 100 random-addition heuristic or

†To whom reprints should be sent at the present address: Department of Biology, University of California, 405 Hilgard Avenue, Los Angeles, CA 90024-1606.

"The sequences reported in this paper have been deposited in the GenBank data base (accession no. U07937). 


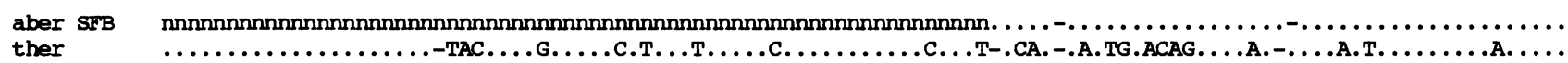

becc IIS TAATCACATA-TTGA-CGCTPTC-ATTAC--GGATAACCGTGGGAA-ACCAAGGCTAATAC-GAGTGAAAAGTGTTGCTGT-CTCAGCAACGCGTAITTCTTGTGTCTT

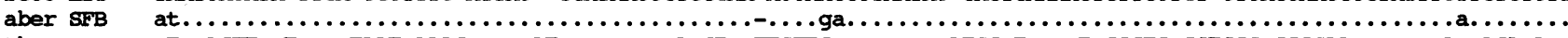

ther

.T. .AGTT. .T. .. TAAT.AAAG. ....AT. ......... CT. .TTGTTG........ATGC.T...T.CCGTG.CCTGCG.CCGGAA......A..AGA.A. .

beCC IIS GAGTCGAA-CGC-GCTCCGGC-GTGTGCGATGAATCGCAAGAACTTITCGAATC--GATG-TCGA--T-CGGT-CAT-A-TT-GGTTPCTGACCTATCAGCTCTCGATG

aber SFB

ther

becc IIS

aber SFB

ther

becc IIS

aber SFB

ther

becc IIS

aber SFB

ther

becc IIS

aber SFB

ther

becc IIS

aber SFB

ther

becc IIS

aber SFB

ther

bece IIS

aber SFB

ther

becc IIS

aber SFB

ther

beco IIS

aber SFB

ther

becc IIIS

aber SFB

ther

becc LIS

aber SFB

ther

becc IIS

aber SFB

ther

becc IIS

aber SFB

ther

becc IIS

aber SFB

ther

.

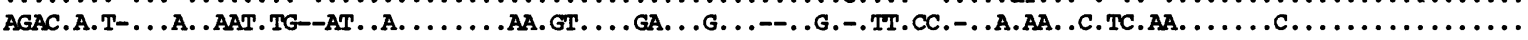
GTGAGGTAITGGCTAACCATGGCGATGACGGTTACGGGGAATTGGGGTHTATTCCGGAGAGGGCGCCTGAGAAATGGCGACCACGTCTAAGG-ATGGCAGCAGGCG . AGT.... ACT. CGCAAATIACCCAATCCTGACACAGGGAGGTAGTGACAAGAAATAGCAACACAAAGC--AC-C-TTGCTIT-GCAAT-G-AT-AG--GCGGITAACTCTCGCTPAGAGT ..............................................................nnnnnnnnnnnnnnnnnnnnnnnnn

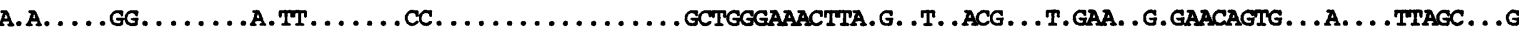

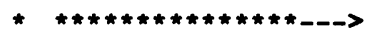

AACAAITGGAGGGCAAGTCA-GGTGCCAGCAGCCGCGG-TAATPCCAGCTCCAATAGCGTATATPAAAG-TTGTT--GCAG-THAAAAAGCTCGTAGITGAA-A-TGAT

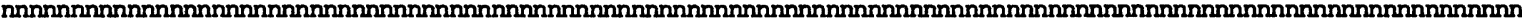

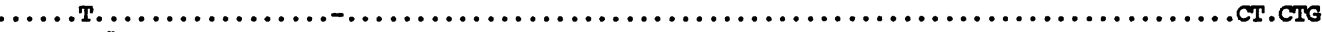
PROBR 1

GAC-T-D_-CGCGAT-TGTTGTAACT-CATG_-T-AG-T-TCA-ACTTHTGTAG__-GTCTGG-CATCA-__-CGATGC-_-TTT-GG-_-TTACTHT

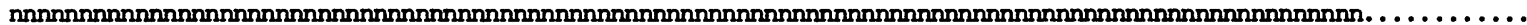

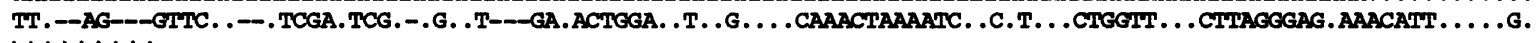

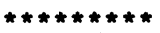
GAGAAAAATAGAGTGTHTCAAGCGGGCAATTGCTGAAATAGTGIACCGTGGAATGACGAAA-AGGCCGCTCTTCTGITTGITGA-CTCTCGGAATTGCGGTGCGTGITG .

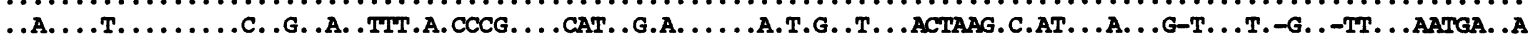
AGAGGAACAGTCGGGGTATTCGTATTGAACAGTCAGAGGTGAAATTCTTAGAITTGITCACGACGAACTAGTGCGAACGATCTACCAAGGATGAITTCAITAATCAA

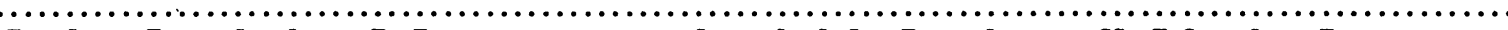
.T...G..........A....T................................G..T.G..............

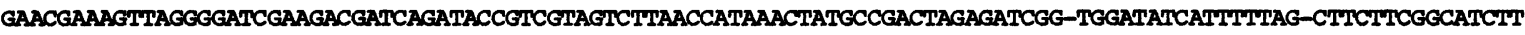

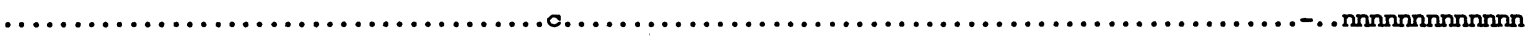

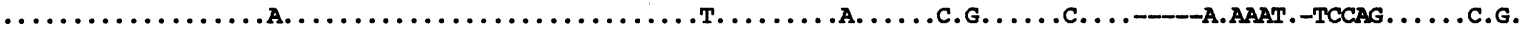

ATGAGAAATCAAAGTCTHTGGGTCTGGGGGAGTATGGT-CGCAAGG-CTGAAACTHAAAGGAATTGACGGAAGGGCACCACCAGGAGTGGAGCCTGCGGCITAAITT

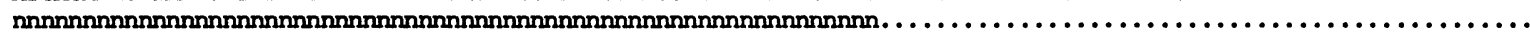

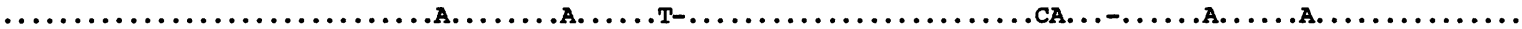

GACTCAACAC-GGGAAATCTCACCAGGTCCGGACATAGGAAGGATTGACAGCTTGAGAGCGCTHTCTTGAITCTATGGGTGTGGTGCATGGCCGTICITAGTTGGTGG

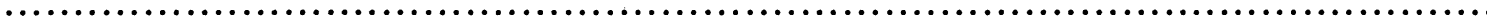

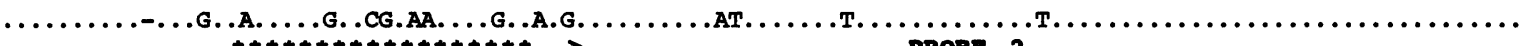

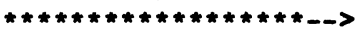
PROB: 2 ATTGATTTGTCTGGTTATTCCGACAACGAACGAGACCTTCGCCAGCTAAATAG-CAGCCCTGTTCT-TGTTACAGGGTAGTCTTCTTAGCGGGACT-TTGTECGT-TC

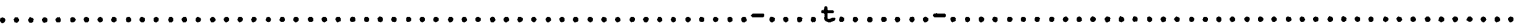

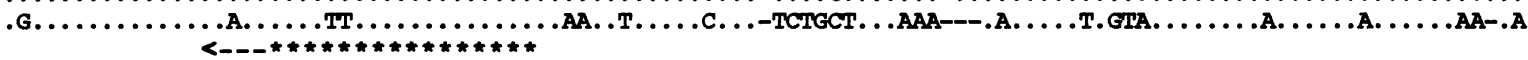
AGCCAA-TGAAG-TGAAGGCATAACAGGTCTGTGATGCCCTPAGATGTTCTGGGCTGCACGCGTGCTACAGTGGAACTCGCACCGAG-TC-GCGAAACTG-D-AGAA

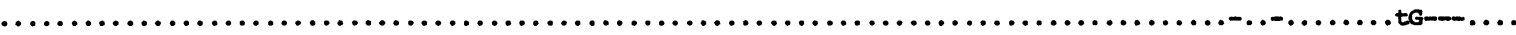
....т...т.

GT-TAAGCG-AATC-TTGGAAAGTGTTCCGTGACCGGACAG-TTGATTGCAATTATTCAACTCGAACGAGGAATCCTPGTAATCGTGATTCATCATATCGCGATGA

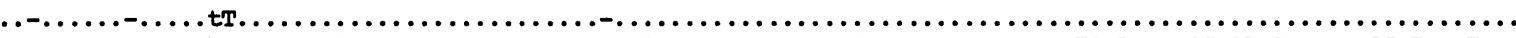

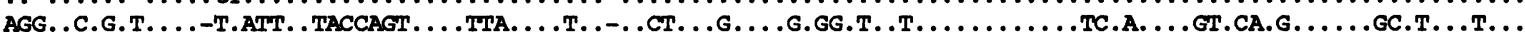

ATACGTCCCTECCCTHTGTACACACCGCCCGTCGCTCCTACCGA--THGGGTGATCCGGTGAATIACTTGGA-ACA-GCCACGATGTCCTATGGATHTCGCGGTCGTGA

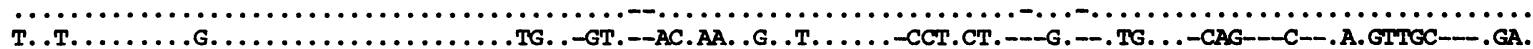

AATGITGIGAACCITATCATCTAGAGGAAGGAAAAGTCGTAACAAGGITICCGGAGGTGAACCTGCAGAAGGATCA-A 1702

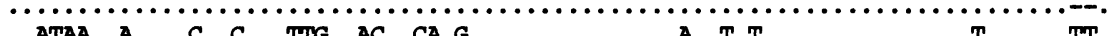

FIG. 1. Nuclear small-subunit (18S) rDNA for Ammonia. Complete 18S rDNA sequence for the benthic foraminifer $A$. beccarii collected from Long Island Sound, New York (LIS), and partial sequence for $A$. aberdoveyensis collected in San Francisco Bay, California (SFB). The first 21 and last 25 nucleotides for $A$. beccarii represent PCR primer sequence. Sequence for the ciliate Tetrahymena thermophila is added for reference. Sequence in italics represents two regions used to generate in situ hybridization probes. Stars above the LIS sequence indicate bases used for probe PCR priming and arrows indicate directionality of primers. Dots represent sequence identity to the top line. Full-scale sequence alignments generated by MALIGN (15) and incorporating all of the taxa in phylogenetic analysis are available from the authors.

exhaustive searches using PAUP (17). Searches were conducted with tree bisection and reconnection search options.

\section{RESULTS AND DISCUSSION}

The complete and partial sequences for $A$. beccarii and $A$. aberdoveyensis are presented in Fig. 1. By using whole mount, DNA in situ hybridization experiments, our probes positively identified the nuclei of $A$. beccarii (Fig. 2). Feulgen staining (16) of $A$. beccarii from identical cultures stained nuclei similar in location and morphology to those labeled using DNA in situ hybridizations. Numerous in situ hybridization control experiments were also conducted. Probes generated for possible PCR contaminants, the dinoflagellate Symbiodinium sp. and the diatom Nitzshia sp., did not label $A$. beccarii, and probes for Symbiodinium sp. successfully labeled the nuclei of this 

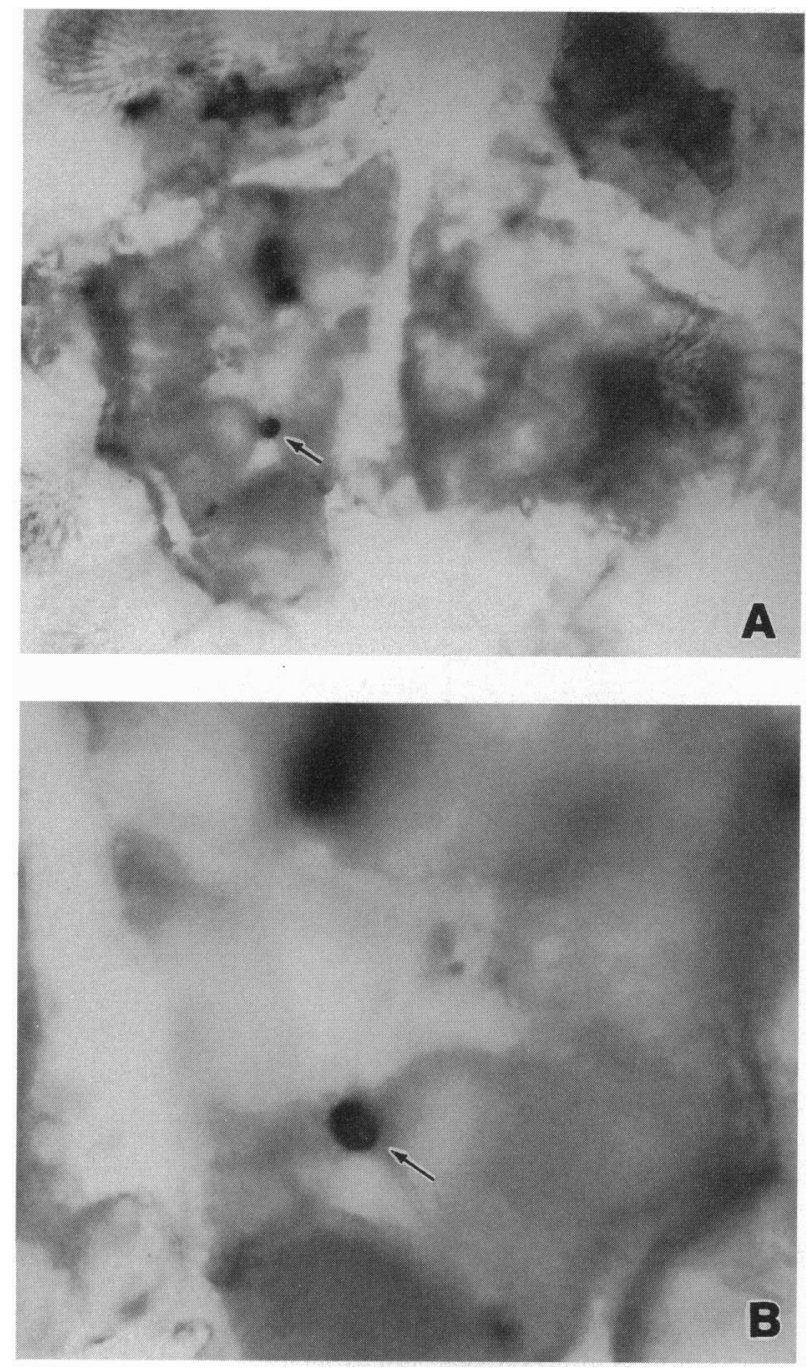

FIG. 2. In situ verification of DNA sequence. $A$. beccarii (LIS) probed with specific $18 \mathrm{~S}$ rDNA digoxigenin-labeled probe no. 1 (see Fig. 1). (A) Whole mount $A$. beccarii crushed in aqueous mount. $(\times 160$.) The nucleus of $A$. beccarii (arrow) is positively labeled with the specific probe generated from the $18 \mathrm{~S}$ rDNA sequence. $A$. beccarii is shown to be a multinucleate foraminifer (other nuclei in different focal plane) through independent tests of the DNA probes and standard Feulgen nuclear staining techniques (ref. 16; not shown). (B) Distinct, labeled nucleus (arrow) of $A$. beccarii. $(\times 330$.)

dinoflagellate. Probe specificity was checked using Southern blot transfer of DNA followed by in situ hybridizations. The individual foraminiferal probes specifically labeled foraminiferal and not diatom or dinoflagellate $18 \mathrm{~S}$ rDNA in $>40^{\circ} \mathrm{C} 0.1 \times$ SSC washes of Southern blots. The in situ hybridization tests and the sequence identity between the two foraminifera (Fig. 1) strongly suggest that both sequences are derived from the nuclear genome of Ammonia.

Extremely high levels of identity between the sequences indicate that $A$. beccarii from North Sea Harbor, Peconic Bay, New York, and $A$. aberdoveyensis from San Francisco Bay, California, are closely related taxa. The 14 differences in the nucleotide sequences, however, characterize them as populations of different species within this morphologically variable, cosmopolitan genus (18).

Phylogenetic analyses of unambiguously aligned nucleotides and complete gene sequences place the foraminifera within the "alveolates" (Fig. 3). The extreme divergence between the foraminiferal and other eukaryotic sequences makes phylogenetic placement of this lineage problematic, and the precise branching order of these foraminifera and the alveolates remains uncertain. Various computer-generated alignments (15) and subsequent phylogenetic reconstructions place the foraminifera as a sister group to the ciliates (Fig. 3) or as a sister group to an apicomplexan/dinoflagellate clade derived after the divergence of the ciliate lineage. Rigorous evaluation of an alveolate sub-tree clarifies relationships within this group. An exhaustive, parsimony-based, reconstruction (Fig. 3) indicates that the foraminifer/ciliate and apicomplexa/ dinoflagellate lineages each share independent common ancestors.

To avoid the assumptions associated with bootstrap resampling $(23,24)$, we examined the robustness of our phylogenies through investigation of Bremer support. Calculation of Bremer support $(25,26)$ indicates there is a moderate amount of evidence placing these foraminifera in association with the alveolates. Strict consensus of phylogenetic hypotheses six steps less parsimonious than our tree finds the alveolates as paraphyletic, but Ammonia remains within the alveolate grade. Therefore, in our analysis there is more phylogenetic support placing these foraminifera together with the alveolates than there is support for a monophyletic alveolate clade. Considering our phylogenetic placement of Ammonia, the absence of cortical alveoli in foraminifera raises nomenclatural difficulties.

The deep branching relationships of the major eukaryote lineages in this (Fig. 3) and previously published phylogenies $(27,28)$ remain difficult to reconstruct using any phylogenetic methodology. However, our phylogeny suggests that Ammonia is more closely related to the alveolates than to Acanthamoeba castellanii. A greater diversity of foraminiferal 18S rDNA sequence will be necessary to obtain a robust molecular view of $(i)$ whether the foraminifera are a monophyletic lineage or (ii) whether foraminifera are closely related to any rhizopod amoebae.

The biflagellated gametes of Ammonia (29) and our data indicate that the lack of flagellar apparatus in adult foraminifera represents a derived loss from a flagellated ancestor. The recent suggestions that the foraminifera may be related to the flagellated marine protist Massisteria marina (bearing branching, granulose pseudopodia) $(19,30)$ are in agreement with our phylogenetic placement of the foraminifera. Finally, the shared characteristics between heterokaryotic foraminifera and karyorelict ciliates (e.g., nuclear dimorphism) suggest a common eukaryotic ancestor with flagellar-based motility (31).

Our findings indirectly demonstrate that reassessment of the relationships within the foraminifera may become necessary. The paleontologic record shows that agglutinated and organic walled foraminifera appear first and give rise to more complex wall types later (32). With no indication of what the naked ancestor of foraminifera might have been, workers have assumed the foraminifera arose from a naked sarcodine amoeba $(10,11)$. This assumption is based upon the logic that the agglutinate and organic walled foraminifera are primitive and are closely related to some amoeba. The assumed association of foraminifera and amoebae is not well supported by our DNA sequence or cytologic data (31). Finally, it is problematic to make phylogenetic assumptions concerning amoeba-like ancestors of the foraminifera because the rhizopod amoebae are considered an artificial group $(33,34)$.

Comparison of molecular phylogenies to the Proterozoic and Cambrian $(8,35,36)$ fossil record indicates that the major eukaryotic radiation greatly predates the first appearance of fossils of many lineages. Inclusion of foraminifera into this major radiation suggests that the lineage could be considerably older than their Cambrian fossils indicate $(8,9)$. However, Cambrian first occurrences of putatively older lineages are common for many eukaryotic groups (36). 

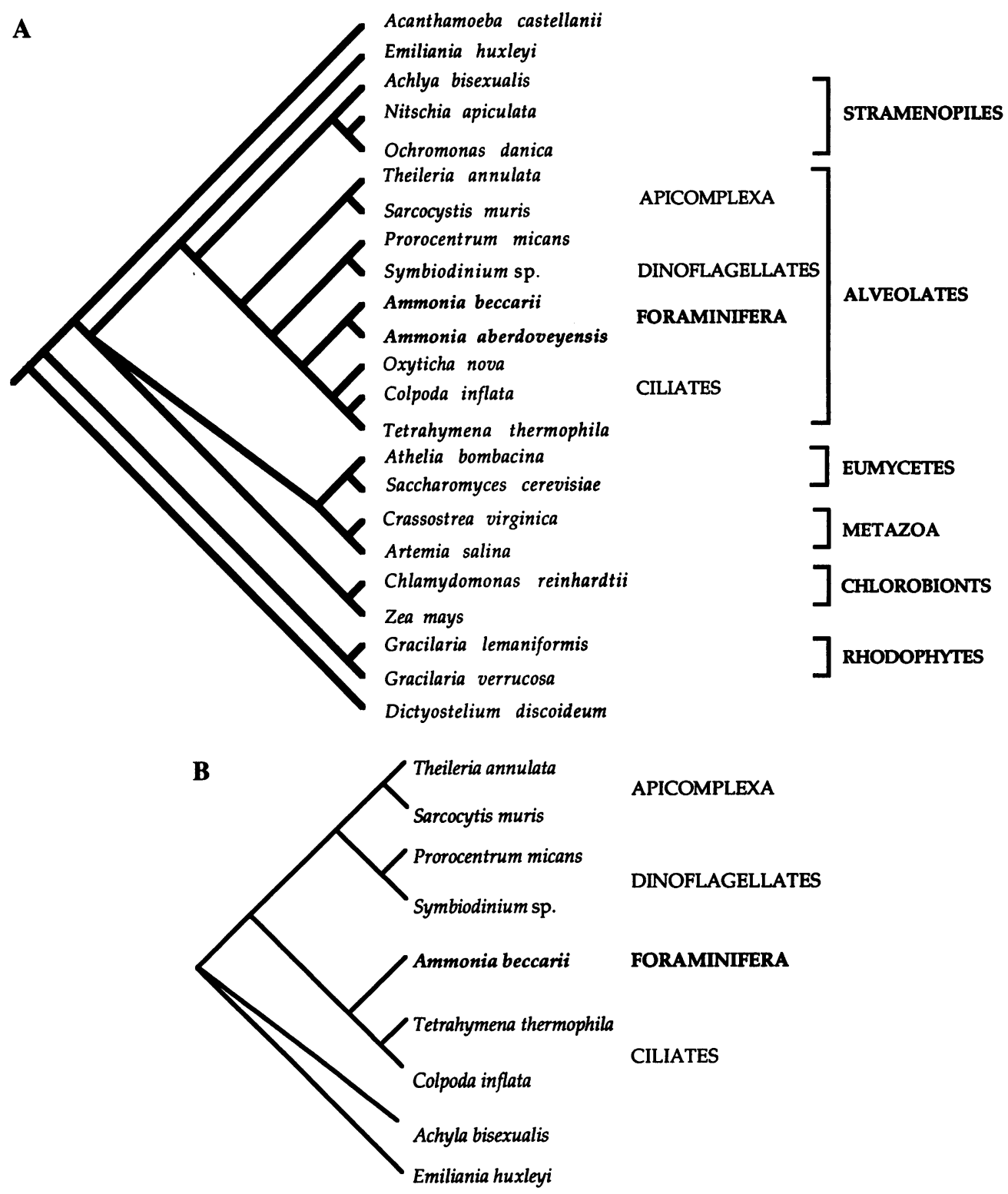

APICOMPLEXA

DINOFLAGELLATES

FORAMINIFERA

CILIATES

FIG. 3. Placement of the foraminifera in the eukaryotes inferred from $18 \mathrm{~S}$ rDNA sequence. Foraminifera, as represented by two sequences for Ammonia, are found as a lineage within the larger "alveolate" (19-21) group. $(A)$ Phylogeny represents analysis of 1647 of 1955 aligned nucleotide positions. All other sequences in analysis were taken from GenBank. The tree represents a strict consensus of two equally parsimonious trees of length 2957 steps, each with a consistency index $(C I)=0.495$ and a retention index $(R I)=0.491$. Phylogenetic analysis of all nucleotide positions of combined alignments [elison (22)] of variable gap-to-change costs also places the foraminifera in association with the alveolates. $(B)$ Phylogeny of the alveolate subgroup. The tree represents the single most parsimonious solution of all positions in alignment, tree length 1942 steps, $\mathrm{CI}=$ 0.771 and $\mathrm{RI}=\mathbf{0 . 4 4 0}$. Analysis of unambiguously aligned positions yields identical topology. Only the complete $A$. beccarii sequence is analyzed in subgroup tests. Bremer support calculation indicates full eukaryote phylogenies up to 6 steps longer, and alveolate subgroup phylogenies up to 10 steps longer still place the foraminifera in the alveolates.

We thank the following people: W. C. Wheeler for assistance in computing sequence alignments, J. W. Taylor for providing equipment and facilities, and M. L. Sogin and G. Hinkle for numerous helpful comments. This work was made possible through a National Aeronautics and Space Administration (NASA) predoctoral fellowship awarded to C.G.W. NASA Grant NAGW3312, Deutsche Forschungsgemeinschaft Grant LA 884/-1 to M.R.L., and W. Storrs Cole award to J.H.L.

1. Lipps, J. H., ed. (1992) Fossil Prokaryotes and Protists (Blackwell, Boston).

2. Zachos, J. C. \& Arthur, M. A. (1986) Paleoceanography 1, 5-26.

3. Savin, S. M., Douglas, R. G. \& Stehli, F. G. (1975) Bull. Geol. Soc. Am. 86, 1499-1510.

4. Bowser, S. S. \& Reider, C. L. (1985) Can. J. Biochem. Cell Biol. $63,608-620$.
5. Lee, J. J. (1990) in Handbook of Protoctista, eds. Margulis, L., Corliss, J. O., Melkonian, M. \& Chapman, D. J. (Jones and Bartlett, Boston), pp. 524-548.

6. Grell, K. G. (1990) Arch. Protistenkd. 138, 271-290.

7. Grell, K. G. (1991) Arch. Protistenkd. 140, 303-320.

8. Lipps, J. H. (1992) in The Proterozoic Biosphere: A Multidisciplinary Study, eds. Schopf, J. W. \& Klein, C. (Cambridge Univ. Press, Cambridge, U.K.), pp. 237-240.

9. Culver, S. J. (1991) Science 254, 689-691.

10. Corliss, J. O. (1994) Acta Protozool. 33, 1-51.

11. Loeblich, A. R. \& Tappan, H. (1964) Treatise on Invertebrate Paleontology Protista 2 Sarcodina Chiefly 'Thecamoebians' and Foraminifera (Geol. Soc. Am. and Univ. of Kansas, Lawrence), Part C.

12. Wray, C. G., DeSalle, R. \& Lee, J. J. (1993) Micropaleontology 39, 69-73. 
13. Langer, M. R., Lipps, J. H. \& Piller, W. H. (1993) Micropaleontology 39, 63-68.

14. Toneguzzo, F., Glynn, S., Levi, E., Mjolsness, S. \& Hayday, A. (1988) BioTechniques 6, 460-469.

15. Wheeler, W. C. \& Gladstein, D. (1991) MALIGN, Alignment Package (Am. Mus. Nat. Hist, New York), Version 1.8.

16. Lee, J. J. \& Pawlowski, J. (1992) in Protocols in Protozoology, eds. Lee, J. J. \& Soldo, A. (Allen, Lawrence, KS), pp. C12-C12.2.

17. Swofford, D. (1991) PAUP, Program and Documentation (Ill. Nat. Hist. Surv., Champaign).

18. Haynes, J. R. (1992) J. Micropaleontol. 11, 59-63.

19. Cavalier-Smith, T. (1993) Microbiol. Rev. 57, 953-994.

20. Patterson, D. J. \& Sogin, M. L. (1992) in The Origin and Evolution of the Cell, eds. Hartman, H. \& Matsuno, K. (World Scientific, River Edge, NJ), pp. 13-46.

21. Wolters, J. (1991) BioSystems 25, 75-83.

22. Wheeler, W. C., Gatsey, J. \& DeSalle, R. (1995) Mol. Phylogenet. Evol. 4, in press.

23. Sanderson, M. J. (1989) Cladistics 5, 113-129.

24. Hillis, D. M. \& Bull, J. J. (1993) Syst. Biol. 42, 182-192.
25. Bremer, K. (1988) Evolution 42, 795-803.

26. Källersjö, M., Farris, J. S., Kluge, A. G. \& Bult, C. (1992) Cladistics 8, 275-287.

27. Wainwright, P. O., Hinkle, G., Sogin, M. L. \& Stickel, S. K. (1993) Science 260, 340-342.

28. Schlegel, M. (1991) Eur. J. Protistol. 27, 207-219.

29. Goldstein, S. T. \& Moodley, L. (1993) J. Foraminiferal Res. 23, 213-220.

30. Patterson, D. J. \& Fenchel, T. (1990) Mar. Ecol. Prog. Ser. 62, 11-19.

31. Orias, E. (1991) BioSystems 25, 67-73.

32. Hansen, H. J. (1979) Lethaia 12, 173-182.

33. Bovee, E. C. \& Jahn, T. L. (1973) in Biology of Amoeba, ed. Jeon, K. W. (Academic, New York), pp. 37-82.

34. Hinkle, G. \& Sogin, M. L. (1993) J. Eukaryotic Microbiol. 40, 599-603.

35. Knoll, A. H. (1992) Science 256, 622-627.

36. Lipps, J. H. \& Signor, P. W., eds. (1992) Origin and Early Evolution of the Metazoa (Plenum, New York). 